\title{
A LINGÜÍSTICA TEXTUAL NA FORMAÇÃO DO PROFESSOR*
}

\author{
Cosme Batista dos SANTOS
}

RESUMO: Este artigo focaliza a reformulação de conceitos da lingüística textual (LT) por professores de língua materna no semi-árido baiano. Especificamente, focaliza as estratégias de reformulação dos conceitos da LT de um texto de divulgação científica, considerado como texto formador, (i) para o discurso oral do professor formador em sala de aula e (ii) para os comentários de duas alfabetizadoras em formação sobre a escrita de seus alunos na escola. Nos discursos do professor formador, observamos que as reformulaçōes realizadas são de natureza explicativa ou didática, objetivando a aprendizagem do conceito. Nos comentários das alfabetizadoras, por outro lado, os conceitos são reformulados com apoio nas categorias da linguagem ordinária, sem incorrer em contradição ou redução dos conceitos básicos. Nesse caso, predomina a reformulação apropriativa, já que os conceitos da ciência são reformulados ao modo dos usuários.

Palavras-chave: Lingüística textual. Reformulação científica. Formação.

\section{TEXTUAL LINGUISTIC IN TEACHER TRAINING}

ABSTRACT: This paper focuses on the construction of the concept of Textual Linguistic (TL) by mother tongue teachers in the semi-arid region of Bahia. It specifically concentrates on the reformulation strategies of concepts from a scientific text for general public, considered as the base text, in 1) the oral discourse of the teacher trainer in the classroom and 2) the comments made by two training teachers about their students' written texts. In the teacher trainer's discourse, reformulations have an explicative or didactic nature aimed at learning. In the oral comments of the training teachers, concepts are reformulated with

\footnotetext{
* Agradeço aos professores, alunos e funcionários do Programa "Rede UNEB", da Universidade do Estado da Bahia (UNEB), pelas informações fornecidas para este artigo.

** Doutor em Lingüística Aplicada pela Universidade Estadual de Campinas (UNICAMP), professor adjunto da uneb e pesquisador do Núcleo Letramento do Professor do IEL/UnicAmp. E-mail:cosmebs@uol.com.br
} 
the help of terms typically used in the ordinary language, without risks of contradictions or reduction of the basic concepts. Reformulations thus have an appropriative nature since the scientific concepts are reformulated according to the users' way

Key words: Textual linguistic. Scientific reformulation. Formation.

\section{Introdução}

E

ste trabalho analisa o impacto de conceitos da lingüística textual na formação do professor alfabetizador. Mais especificamente, ele analisa a reformulação de conceitos da lingüística textual nas práticas, com o foco na relação entre o conceito de continuidade tópica, tal como é textualizado em um texto escrito utilizado como objeto de leitura durante a formação dos professores alfabetizadores, e as reformulaçōes desse conceito pelo professor formador, na prática de formação, e pelos alfabetizadores em formação, no contexto escolar.

Trata-se de uma análise com foco nas estratégias de reformulação didática da noção teórica de continuidade de um texto de divulgação científica, considerado como o texto escrito formador para o discurso oral da professora formadora, produzido em um curso de formação continuada para alfabetizadores e, ainda, para o discurso oral de duas alfabetizadoras em formação, produzido a partir de intervenções nas redaçôes de seus alunos. Desejamos saber, sobretudo, quais as transformaçóes que esse conceito sofre todas as vezes que ele é atualizado em cada uma dessas instâncias específicas de enunciação.

Estudos antecedentes mostram que a atividade de retextualização, transposição e reformulação de conceitos de um texto escrito acadêmico para outros textos ou usos (Marcuschi, 2001; Matêncio, 2002) ou, especificamente, para uma situação de ensino (Rafael, 2001; Aparício, 2001) tende a ser afetada por fatores lingüísticos, sociais e cognitivos, dentre os quais podemos citar: (a) os gêneros e as modalidades em uso (da fala para a escrita etc.); (b) os eventos de letramento específicos em que o termo ou o conceito científico é reutilizado (nas práticas de formação, nas práticas escolares, nas práticas jornalísticas etc.) e (c) o letramento específico ou tipo de relação que os leitores, no papel de agentes reformuladores (Peytard, Jacobi \& Petroff, 1984), mantêm com o conceito original (especialistas ou não especialistas na área de conhecimento tratada). 
Os resultados deste trabalho devem ampliar as descobertas acerca da retextualização e reformulação de conceitos na formação e no ensino, considerando alguns aspectos que ainda não foram devidamente focalizados nos estudos antecedentes, a saber: em primeiro lugar, focaliza a reformulação de definições da ciência lingüística, em um contexto notadamente marcado pela tradição oral, como é o caso das pequenas cidades do semi-árido baiano; em segundo lugar, focaliza as reformulações de uma mesma definição por leitores ou usuários com formação distinta (letras e magistério) em dois contextos diferentes (na prática de formação e na escola) e, por último, contribui com a formação lingüística do professor alfabetizador, potencializando-o para a prática do ensino e avaliação da escrita do aluno.

Estamos mobilizando, também, como pressuposto, a visão dialógica da leitura, ou seja, concebendo-a como atividade social situada nas interações específicas. Nesse sentido, a leitura de um texto acadêmico, mais do que uma simples decodificação e de uma pacifica coleta de definições no interior do texto, é uma atividade responsiva, no sentido bakhtiniano do termo, podendo envolver evidentemente reformulação e apropriação, no sentido dado por Certeau (1994).

Com base nos aspectos apontados nesta introdução, organizamos este artigo em três partes. Na primeira, apresentaremos um quadro teórico reunindo e ampliando os pressupostos teóricos vinculados ao tema central reformulação científica; na segunda, analisaremos as reformulações do conceito de continuidade tópica no texto escrito formador, no discurso da professora formadora, nos comentários das professoras alfabetizadoras focalizadas e, além disso, as relações existentes entre cada reformulação realizada; na terceira e última parte, apresentaremos as nossas considerações finais relativas aos resultados do estudo.

\section{Reformulação e construção do conceito}

O quadro de pressupostos selecionados foi montado com base numa visão dialógica da escrita (Bakhtin, 1995; Koch, 1997; Marcuschi, 1999), a qual pode ser focalizada inclusive nas interações verbais mediadas pelos textos acadêmicos e/ou científicos. Nesse sentido, a divulgação de um conceito científico, seja pelo próprio autor, seja por terceiros, implica reformulações decorrentes das condições de difusão ou especificamente da influência dos interlocutores na construção da significação. 
A reformulação dos conceitos pode ocorrer nas situações diversas de difusão, a partir do momento em que os termos científicos ou técnicos são reutilizados em domínios distintos e, conseqüentemente, são adaptados para atender aos diversos níveis de compreensão dos destinatários (Brey, 1984; Petroff, 1984), ou pode ocorrer sob o efeito de uma transposição didática, a partir do momento em que tais termos são atualizados para fins específicos do ensino/aprendizagem escolar (Bronckart \& Giger, 1998). A reformulação resultante das práticas de difusão pode se manifestar em situações variadas como, por exemplo, naquelas em que um determinado manual que contém termos altamente técnicos é reformulado para melhorar a compreensão dos seus leitores, na condição de destinatários pré-estabelecidos. A reformulação sob o efeito de uma transposição didática manifesta-se nas situaçôes específicas de ensino como, por exemplo, nas situações em que os professores de língua portuguesa mobilizam terminologias de gramática tradicional para tornar os conceitos teóricos da lingüística mais acessíveis para os alunos (Rafael, 2001; Aparício, 2001).

Neste estudo, considerando que os comentários das alfabetizadoras em formação sobre a escrita não se configuram propriamente numa situação de difusão ou de ensino, estamos sugerindo a possibilidade de outro tipo de reformulação que podemos chamar de reformulação apropriativa, considerando os casos em que o conceito científico é reformulado à maneira do leitor pelo uso que se faz dele (Certeau, Giard \& Mayol, 1996). Esta estratégia pode se manifestar nos casos em que o leitor se apropria do conhecimento científico, mobilizando basicamente os termos da linguagem ordinária, resultando, muitas vezes, em um enriquecido processo de construção metafórica. Os conceitos podem ser reformulados não necessariamente sob o efeito de uma difusão ou de uma transposição, mas, sobretudo, sob a influência da ação responsiva do interlocutor (Bakhtin, 1995), ao inserir na sua interpretação as palavras e as vozes próprias que, por sua vez, sinalizam reformulação, construção e apropriação do conhecimento advindo do texto alheio.

\section{A continuidade tópica na formação e na escola}

Considerando que o foco principal de análise serão as reformulações do conceito de continuidade tópica pela professora formadora Luciana (nome fictício) e pelas alfabetizadoras em formação Laura e 
Indira (nomes fictícios), não vamos analisar a configuração desse conceito, tal como ocorre no texto escrito formador. O conceito textualizado no texto escrito formador será estrategicamente considerado como o ponto de partida das reformulaçóes ulteriores, devendo ser, conseqüentemente, apenas objeto de comparação nesta análise. Assim, a análise dos dados está organizada da seguinte forma: a) apresentação do conceito de continuidade tópica, tal como é divulgado no texto escrito; b) análise das reformulações desse conceito na exposição da formadora Luciana e c) análise das reformulações desses conceitos nos comentários de Laura e Indira.

\section{O conceito de continuidade tópica no texto escrito formador}

Inicialmente, é importante salientar que a denominação texto básico está sendo empregada, neste trabalho, por ser o ponto de partida ou a base de conceitos para as retextualizações. Trata-se de uma estratégia metodológica e, por isso, não deve ser entendido como a fonte ou a origem dos conceitos, tal como é concebida nos estudos acerca da reformulação e vulgarização científica (Peytard, Jacobi \& Petroff, 1984).

Para efeito de uma breve caracterização, o texto original, como já foi indicado na metodologia, é o capítulo II, "Como avaliar a textualidade", da 2a edição do livro Redação e textualidade, de Maria das Graças Costa Val, reeditado por Martins Fontes, em 1999. Neste capítulo, a autora textualiza, baseando-se em Charolles (1978), o conceito de continuidade tópica, conforme podemos ver no exemplo abaixo.

(...) a continuidade diz respeito à necessária retomada de elementos no decorrer do discurso. Tem a ver com a sua unidade, pois um dos fatores que fazem com que se perceba um texto como um todo único é a permanência, em seu desenvolvimento, de elementos constantes. Uma seqüência que trate a cada passo de um assunto diferente certamente não será aceita como texto. Quanto à coerência, esse requisito se manifesta pela retomada de conceitos e idéias. Quanto à coesão, pelo emprego de recursos lingüísticos específicos, tais como a repetição de palavras, o uso de artigos definidos ou pronomes demonstrativos para determinar entidades já mencionadas, o uso de pronomes anafóricos e de outros termos vicários (como os pró-verbos ser e fazer e os pró-advérbios lá, ali, então etc.), a elipse de termos facilmente recobráveis, entre outros mecanismos. (p. 21)

Educ. Soc., Campinas, vol. 27, n. 97, p. 1327-1338, set./dez. 2006 
Assim, a continuidade consiste, segundo a autora, na retomada de elementos, ou seja, na retomada de tópicos ao longo do discurso, devendo ser considerada um dos requisitos necessários para o estabelecimento da textualidade em um texto.

O conceito de continuidade, embora seja, ao mesmo tempo, requisito de coesão e coerência, conforme a autora, pode se manifestar distintamente em cada um desses planos. No plano da coerência, a continuidade manifesta-se pelas retomadas de conceitos e idéias e, por outro lado, no plano da coesão, a continuidade manifesta-se pelo emprego de recursos lexicais e gramaticais utilizados para retomar os tópicos ao longo do texto.

\section{O conceito de continuidade tópica na formação}

O conceito de continuidade tópica foi transposto na situação de formação pela professora formadora Luciana, da seguinte forma:

1. I... continuidade de um texto... ela se dá pelos

2. pronomes... anafóricos...o estudo dos

3. pronomes... partindo do conceito básico... de

4. que pronome... é aquela palavrinha que

5. substitui o nome... é:::então... pelos

6. pronomes... pelas elipses... pelo artigo

7. definido... aquela questão que a gente

8. colocava... o sintagma nominal... o

9. determinante... mas o referencial... não

10. era?... as recorrências... ou seja... as

11. retomadas de ((itens)) lexicais ou

12. gramaticais... retomadas por substantivos

13. ou por termos gramaticais... lembram disso

14. também... né? (Luciana, 2001)

No seu enunciado, a professora formadora Luciana define a continuidade como sendo as "recorrências ou retomadas de itens lexicais ou gramaticais" (linhas 10, 11, e 12), como também é definida no texto escrito. 
De acordo com o texto escrito, como vimos, a continuidade manifesta-se distintamente na coerência e na coesão. Na coerência, pela retomada de conceitos e idéias e, na coesão, pelo emprego de recursos lexicais e gramaticais específicos. Na reformulação desse conceito na sala de aula, Luciana não introduz o conceito nessa mesma ordem. Entretanto, em relação aos termos mobilizados, não constatamos diferenças muito marcantes.

No enunciado da formadora, há situaçôes em que os termos ou opções lexicais do texto escrito formador são retomados e há uma situação em que um dos termos do conceito original é associado a termos da gramática tradicional, visando tornar o conceito mais compreensível para o destinatário, configurando a reformulação didática (Brey, 1984). A primeira situação justifica-se pela mobilização do termo "anafórico", para designar os pronomes que são empregados no texto como mecanismos de continuidade, e pela mobilização dos termos "recorrências" e "retomadas", para designar a função dos itens lexicais e gramaticais na configuração do requisito da continuidade, conseqüentemente na coerência e na coesão textuais. A segunda situação justifica-se pela inserção do termo "substantivos" (linha 12) da gramática normativa para substituir o termo "lexicais" na expressão "retomadas lexicais" do texto escrito. Neste caso, o termo "lexical" empregado no texto escrito na categorização da coesão lexical é atualizado com o apoio do termo "substantivo", advindo da gramática normativa. No texto base, bem como na lingüística do texto, o termo "lexical" é associado aos processos de nominalização (reiteração, substituição e associação), especificamente, apontados como a manifestação da continuidade na coesão textual. Na gramática normativa e na maioria dos livros didáticos, por outro lado, o termo substantivo é definido como a palavra que nomeia os seres, coisas e idéias. Trata-se de uma definição bastante presente no contexto do ensino de língua portuguesa. Dessa forma, a textualização do termo "substantivos" pela professora formadora, na aula, não obscurece o conceito de continuidade tópica do texto escrito formador e parece torná-lo ainda mais compreensível na prática de formação. Nesse caso, parece ocorrer uma reformulação didática do conceito original, em que o conceito é explicitado com apoio em um termo da gramática, tradicionalmente conhecido pelos alunos.

\section{$\mathrm{O}$ conceito de continuidade tópica na escola}

Nesta seção, analisaremos o conceito de continuidade tópica nos comentários das alfabetizadoras Laura e Indira. Em outros termos, a nossa 
preocupação nessa análise recai sobre as estratégias utilizadas por tais alfabetizadoras para reconfigurar o conceito acessado por meio do texto escrito formador e por meio do texto oral da professora formadora.

(3) O comentário da alfabetizadora Laura:

1. o texto ta bom... tem

2. coerência... você não acha?...

3. (.) ta sempre no assunto... um

4. assunto está puxando o

5. outro... ela/ela... desviou que

6. tava convidando ela pra o

7. aniversário... eu acho que ta

8. combinando com o aniversário

9. ((o título do texto da aluna é "O

10. meu aniversário")) não tem

11. palavras soltas...

No enunciado acima, iniciando o seu comentário, Laura constata que o texto do seu aluno "ta bom" e, logo em seguida, acrescenta que o texto "tem coerência" (linhas 1 e 2). Nesse caso, parece ficar evidente que para Laura a coerência textual é um critério fundamental na organização do texto. A coerência é, nesse sentido, uma condição básica para a textualidade. Essa crença atravessa todos os discursos sobre a textualidade circulados na formação, principalmente o texto escrito formador que aponta que a coerência é o "fator fundamental da textualidade, porque é responsável pelo sentido do texto" (Costa Val, 1999, p. 21). No entanto, o que nos interessa no enunciado acima é o critério de coerência mobilizado por Laura para justificar a coerência textual, os termos empregados na construção do significado e a relação estabelecida com o conceito do texto escrito. No seu comentário sobre o texto do aluno, ela mobiliza apenas o requisito da continuidade tópica como critério para garantir a coerência do texto.

Diferentemente de como ocorre no texto escrito formador e no texto oral da professora formadora, o conceito é construído com o apoio de termos advindo da linguagem cotidiana, envolvendo metáforas e rodeios próprios. $\mathrm{O}$ conceito de continuidade tópica, que é apresentado no texto escrito como sendo a "retomada de conceitos e idéias" e parcial- 
mente reformulado no texto da professora formadora como sendo "as retomadas de itens lexicais e gramaticais", é mantido no texto de Laura. No entanto, essa manutenção ocorre por meio da mobilização de estruturas bem mais distantes do conceito original, como mostram os seguintes exemplos: "tá sempre no assunto", "um assunto ta puxando o outro" e "não tem palavras soltas" (linhas 3, 4 e 5). Os termos "sempre" e "assunto" substituem, respectivamente, os termos "continuidade" e "tópico", sinalizando que o texto apresenta continuidade de tópicos, de idéias e conceitos; o termo "puxando" substitui o termo "retomada", sinalizando que, no texto, a continuidade manifesta-se pelas retomadas dos referentes ao longo do texto e, por último, a expressão "não tem palavras soltas", sinalizando que o texto apresenta unidade ou coesão lexical.

(4) O comentário da alfabetizadora Indira:

1. ... o texto não é coerente... eu não

2. achei não... (.) porque ela... ela

3. foge um pouco... muda

4. assim... não desenvolve as idéias

5. que ela coloca...ela vai pondo

6. assim... sobrepondo... é:::frases....

Neste enunciado, o foco central é a mobilização de critérios e termos pela alfabetizadora Indira para justificar a falta de coerência no texto do aluno. Retornando, então, à análise dos critérios de coerência mobilizados no comentário de Indira, observamos que, ao justificar a falta de coerência no texto, são mobilizadas as seguintes estruturas: "ela foge um pouco... muda assim" (linha 2). Nessas expressões, os termos "foge" e "muda" são mobilizados para sinalizar a descontinuidade (ausência de continuidade das idéias) que compromete a coerência no texto do aluno. No comentário de Indira, portanto, está subentendido que, assim como é previsto nos textos formadores, um texto para ser coerente necessita da continuidade e, para isso, não foge e não muda o tópico tratado no texto.

Nos enunciados das alfabetizadoras Laura e Indira, focalizando, especialmente, a mobilização dos termos para reconceituar a continuidade tópica, como requisito da coerência textual, constatamos a tendên- 
cia a uma reformulação do tipo apropriativa, na medida em que o conceito é construído basicamente com apoio na linguagem oral, ou seja, com o emprego de palavras e expressôes metafóricas da linguagem cotidiana. Nesse caso, configura-se uma cena em que as alfabetizadoras em formação, na condição de leitoras, demarcam o seu lugar como co-autoras, na construção do saber sobre o texto, ou seja, do saber lingüístico relevante para a sua formação.

\section{Considerações finais}

A reformulação do conceito de continuidade tópica aqui analisada adquire configurações distintas, conforme o contexto de uso. $\mathrm{Na}$ formação, as reformulações tendem a ser menos salientes, considerando que a professora formadora, em seu discurso, conserva muitas estruturas e termos da escrita, tais como circulam no texto escrito: "retomada de idéias", "tópico-comentário", "recorrências de termos" etc. e, nas intervenções das professoras alfabetizadoras em formação, as reformulações são mais situadas, considerando que, em seus comentários, as estruturas e os termos empregados no texto escrito são praticamente substituídos por outros tipicamente usados na linguagem comum: "um assunto ta... puxando o outro", "ela foge... do assunto", "não tem palavras soltas" etc.

$\mathrm{Na}$ primeira situação, configura-se uma reformulação com fins didáticos, uma vez que a mobilização de termos da gramática normativa, por exemplo, visa facilitar a compreensão da noção de continuidade tópica. $\mathrm{Na}$ segunda situação, por outro lado, configura-se uma reformulação de natureza apropriativa, considerando que os conceitos são reformulados à maneira dos usuários, com apoio em metáforas e expressões do cotidiano.

Portanto, embora preliminares, tais resultados sugerem que o estudo do impacto das noções teóricas, em especial da lingüística textual, na formação do professor de língua materna deve ter como foco não apenas as estratégias de retextualização e transposição dos conceitos lingüísticos, como também as reformulações que o professor faz em tais noções para acomodá-las em suas manifestações orais.

Recebido em novembro de 2005 e aprovado em março de 2006. 


\section{Referências bibliográficas}

APARÍCIO, A.S. As ações didático-discursivas do professor para a construção e manutenção dos tópicos em aula de gramática. In: KLEIMAN, A.B. (Org.). A formação do professor: perspectivas da lingüística aplicada. Campinas: Mercado de Letras, 2001.

BAKHTIN, M. Tema e significação na língua. In: BaKHTIN, M.M. Marxismo e filosofia da linguagem. São Paulo: Hucitec, 1995.

BREY, C. Les travaux pratiques de reformulation. Langue Française, Paris, n. 64, p. 68-80, 1984.

BRONCKART, J-P.; GIGER, I.P. La transposition didactique: histoire et perspectives d'une problèmatique fondatrice. Pratiques, Metz, n. 97, p. 35-58, 1998.

CERTEAU, M. A invenção do cotidiano: artes de fazer. Petrópolis: Vozes, 1994.

CERTEAU, M. A cultura no plural. Campinas: Papirus, 2001.

CERTEAU, M.; GIARD, L.; MAYOL, P. A invenção do cotidiano: morar, cozinhar. Petrópolis: Vozes, 1996.

CHAROLLES, M. Introdução aos problemas da coerência dos textos: abordagem teórica e estudo das práticas pedagógicas. In: GALVES, C.; Orlandi, E.P.; Otoni, P. O texto: leitura e escrita. Campinas: Pontes, 1978.

COSTA VAL, M.G. Redação e textualidade. 2. ed. São Paulo: Martins Fontes, 1999.

JACOBI, D. Du discours scientífique, de sa reformulation et de quelques usages sociaux de la ciencia. Langue Française, Paris, n. 64, p. $68-80,1984$.

KOCH, I.V. O texto e a construção dos sentidos. São Paulo: Contexto, 1997.

MARCUSCHI, L.A. Cognição, explicitude e autonomia no texto falado e escrito. In: Moura, D. (Org.). Os múltiplos usos da língua. Maceió: UFAL, 1999. p. 38-48. 
MARCUSCHI, L.A. Da fala para a escrita: atividades de retextualização. São Paulo: Cortez, 2001.

MATÊNCIO, M.L. Atividade de (re)textualização em práticas acadêmicas: um estudo sobre o gênero resumos. Comunicação apresentada no II. Simpósio Internacional sobre Análise do Discurso, Belo Horizonte: UFMG. 8-10 maio 2002.

PEYTARD, J.; JACOBI, D.; PETROFF, A.J. (Org.). Français technique et scientifique: reformulation ensignement. Langue Française, Paris, n. 64, p. 5-16, 1984.

PÉTROFF, A.J. Semiologie de la reformulation dans le discours scientifique et technique. Langue Française, Paris, n. 64, p. 68-80, 1984.

RAFAEL, E.L. Construção dos conceitos de texto e de coesão textual: da lingüística à sala de aula. 2001. Tese (Doutorado) - Instituto de Estudos da Linguagem, Universidade Estadual de Campinas, Campinas.

RAFAEL, E.L. Atualização em sala de aula de saberes lingüísticos de formação: os efeitos da transposição didática. In: Kleiman, A.B. (Org.). A formação do professor: perspectivas da lingüística aplicada. Campinas: Mercado de Letras, 2001.

SANTOS, C.B. A avaliação de redações na escola: uma experiência no semi-árido baiano. In: Kleiman, A.B. (Org.). A formação do professor: perspectivas da lingüística aplicada. Campinas: Mercado de Letras, 2001.

SANTOS, C.B. A construção do conceito de coerência textual por professores em formação no semi-árido baiano. Trabalhos em Lingüística Aplicada, Campinas, n. 41, p. 91-103, 2003.

SANTOS, C.B. Um assunto puxa o outro: a representação da coerência textual pelo professor em formação. 2005. Tese (Doutorado) - Instituto de Estudos da Linguagem, Universidade Estadual de Campinas, Campinas. 